Pre-proof version: Anwar McHenry, J and Donovan, R. 2013. Developing the Perth Charter for the Promotion of Mental Health and Wellbeing. Advances in Mental Health. 12 (1): pp. 8-10.

\title{
Developing the Perth Charter for the Promotion of Mental Health and Wellbeing
}

\author{
Julia Anwar McHenry \\ School of Psychology and Speech Pathology, Curtin University, Perth, Western Australia. \\ (julia.anwarmchenry@curtin.edu.au)
}

\section{Robert J Donovan}

Mentally Healthy WA, Centre for Behavioural Research in Cancer Control, Curtin University, Perth, Western Australia.

\begin{abstract}
While the Ottawa Charter for Health Promotion promotes a holistic approach to health promotion, health promotion in practice has largely been confined to physical health promotion. Hence the organising committee for the 7th World Conference on the Promotion of Mental Health and Prevention of Mental and Behavioural Disorders (held 17-19 October 2012 in Perth, Western Australia) decided to develop a "Perth Charter for Mental Health Promotion and Wellbeing", which has just been published in the International Journal of Mental Health Promotion (http://dx.doi.org/10.1080/14623730.2013.810402). It was hoped that the Perth Charter for Mental Health Promotion would be helpful as a first step towards eventual integration of physical and mental health promotion. The Charter was designed to be succinct and actionable, and was developed in three phases through an iterative feedback process with input from health professionals around the globe. The Perth Charter is intended to be a useful resource for mental health professionals in advocating for greater resource allocation and policy support for mental health, and mental health promotion in particular at a local level. It was envisaged that the Perth Charter would do for mental health promotion what the Ottawa Charter did for health promotion generally, and physical health promotion in particular. An abridged version of the Perth Charter is provided within this review, while the full version is available for download from the Clifford Beers Foundation (http://www.perth2012.org/charter.html) or from Dr Julia Anwar McHenry (julia.anwarmchenry@curtin.edu.au).
\end{abstract}

Key Words: Mental health promotion; health promotion charter; Perth Charter; wellbeing; health promotion policy;

\section{Developing the Perth Charter for the Promotion of Mental Health and Wellbeing}

For those interested in increasing the focus on promoting mental health, the Perth Charter for Mental Health Promotion has just been published in the International Journal of Mental Health Promotion (http://dx.doi.org/10.1080/14623730.2013.810402). While the Ottawa Charter for Health Promotion promotes a holistic approach to health promotion, health promotion in practice has largely been confined to physical health promotion. Hence the organising committee for the 7th World Conference on the Promotion of Mental Health and Prevention of Mental and Behavioural Disorders (held 17-19 October 2012 in Perth, Western Australia) decided to develop a "Perth Charter for Mental Health Promotion and Wellbeing". It was hoped that a separate mental health promotion charter would be helpful as a first step towards eventual integration of physical and mental health promotion. It was envisaged that the Perth Charter would do for mental health promotion what the Ottawa Charter did for health promotion generally, and physical health promotion in particular. 
The Charter was designed to be succinct and actionable, and was developed in three phases through an iterative feedback process with input from health professionals around the globe. Phase One used qualitative methodologies, including two facilitated workshop sessions held in Perth, Western Australia, to develop initial draft principles. The workshops suggested an initial 10 principles which were circulated via email to a broad representation of selected stakeholders (most of whom were based in Australia). These stakeholders were asked to consider the concept of a mental health promotion charter and to provide open-ended feedback on each of the principles. To avoid duplication of existing health promotion charters and to provide a context for a charter focusing on mental health promotion, all participants were asked:

to consider the strengths and weaknesses of the Ottawa Charter for mental health promotion advocacy, as well as the impact and possible areas of unmet need from subsequent Charters, such as the Jakarta Charter, and the Melbourne Charter for Mental Health Promotion.

Using the data collected from Phase One, a full first draft of the Charter (including a preamble, vision, and eight principles) was developed. Both prompted and open-ended feedback on on this draft was obtained via two online surveys of participants recruited from the email and membership lists of the Clifford Beers Foundation and Mentally Healthy WA, and, via a snowball technique, their extended networks. Along with open-ended comments on content and language, respondents were presented with each principle in turn and asked whether they considered the principle 'essential, desirable (but not essential), or not relevant for inclusion in a Perth Charter for Mental Health Promotion'. Extensive feedback received from the first online survey $(n=220)$ on the content, wording and length of the principles was incorporated into a substantial revised second set of seven principles for the second online survey $(n=117)$. Responses were received from 15 countries $(74 \%$ from Australia). All of the seven revised principles received strong support from respondents, and particularly from practitioners, with $85-100 \%$ classifying each as 'essential'. Feedback from the online surveys was incorporated into a final draft which was presented at the closing plenary session of the Conference on 19 October 2012, along with the results of the second Phase Two survey showing the levels of support for each component of the Charter, and each of the principles. Conference attendees were also sent by email a copy of the Perth Charter and an invitation to continue to provide ongoing feedback in order to continually update and revise the Charter to maintain its relevance and applicability over time.

The Perth Charter is intended to be a useful resource for mental health professionals in advocating for greater resource allocation and policy support for mental health, and mental health promotion in particular at a local level. The Perth Charter for the Promotion of Mental Health and Wellbeing is available for download from the Clifford Beers Foundation (http://www.perth2012.org/charter.html) or from $\mathrm{Dr}$ Julia Anwar McHenry (julia.anwarmchenry@curtin.edu.au). An abridged version of the Perth Charter is provided below. 
Pre-proof version: Anwar McHenry, J and Donovan, R. 2013. Developing the Perth Charter for the Promotion of Mental Health and Wellbeing. Advances in Mental Health. 12 (1): pp. 8-10.

\section{Perth Charter for the Promotion of Mental Health and Wellbeing}

(abridged version)

\section{Vision: A world where mental health and physical health are equally valued}

\section{Preamble: The need for a mental health promotion charter}

Despite the World Health Organisation's holistic definition of health, the mental, emotional, psychological and social components of this state of wellbeing receive limited attention. Hence, despite the inseparable nature of physical and mental health, there is a need for a mental health promotion charter to allocate resources more equitably across physical and mental health. This Charter is timely to accelerate this attitude change and to ensure that policy moves beyond rhetoric to specific actions, particularly with respect to the social determinants of health and wellbeing.

\section{Principle 1: Mental health is more than the absence of mental illness. Mental health} promotion includes both preventing illness and increasing wellbeing.

Good mental health not only enhances quality of life and wellbeing but also ensures greater resilience when individuals and communities are faced with stressors. It therefore makes good economic sense to build individual and community mental health and wellbeing from an early age and across the lifespan.

\section{Principle 2: The foundations of social and emotional wellbeing develop in early childhood and must be sustained throughout the lifespan}

Mental health starts at conception and is built on throughout the life cycle. Mental health promotion should be incorporated throughout the lifespan via activities in pre-school nurseries and settings, schools, colleges, universities, workplaces, other social institutions and community organisations. A comprehensive approach should include education, environment, transport, housing, workplaces and employment services, community services, alcohol and other drugs services, welfare organisations and emergency services, health support groups, religious organisations, and sporting, arts, and recreational groups.

Principle 3: Mental health promotion must be integrated with public health and requires a cross-sectoral approach

Given the strong relationship between mental health and issues such as substance abuse, self-harm and suicide, and various non-communicable diseases and their self-management, it is essential that mental health promotion be integrated into public health interventions. Similarly, social determinants such as homelessness, lack of education, poverty, violence, joblessness and job insecurity, discrimination, and so on, influence and are influenced by both mental and physical health. Opportunities for mental health can be planned for proactively through mental health impact assessment across all sectors of civic society and public policy.

Principle 4: Mental health and illness are constructed, experienced and viewed as different to physical health and illness.

Despite the inseparability of physical and mental health, in reality more is known about physical health and illness than mental health and illness because far more is known about how the body works than is known about how the mind works. Furthermore, far more is understood, researched, and discussed about mental illness than mental health. The promotion of mental health and wellbeing must therefore work to reduce these real and perceived differences at all levels from the general public to the highest levels of government. There is also a need to increase resources for research to provide the evidence base for effective mental health promotion interventions. 


\section{Principle 5: Mental health and mental illness are a dynamic balance.}

Mental health and illness should be thought of as two dimensions rather than a single continuum. Mental health and illness is about ebb and flow, with independent fluctuations of levels of wellbeing and symptoms of illness from time to time. Thus a key consideration is how a mentally healthy balance can be managed and maintained over time and during periods of illness and recovery.

\section{Principle 6: Destigmatisation of mental illness and addressing discrimination are essential components of mental health promotion}

Stigma surrounding "mental health problems" and "mental illness" causes distress to those with a mental illness, inhibits help seeking by those in need, leads to discrimination against those with a mental illness, impedes recovery, and obstructs communication and education about the positive messages of mental health promotion. Destigmatisation requires the reorientation of all public services, including the enactment of disability, equalities and anti-discrimination legislation.

\section{Principle 7: Mental health promotion must take place at the individual and societal levels.}

Mental health promotion includes the building of individual skills and coping strategies. Populationbased and community programs should focus on the social environment and how individuals, families and communities can foster and maintain their own mental health and the mental health of those with whom they interact. That is, given the opportunity, everyone can take actions to improve and maintain their own mental health and can influence the mental health and wellbeing of others. 